\title{
LOS ESPACIOS DE RESERVA EN LA EXPANSIÓN GLOBAL DEL CAPITAL. EL SUR-SURESTE MEXICANO DE CARA AL PLAN PUEBLA-PANAMÁ FELIPE TORRES Y JOSÉ GASCA (COORDS.) IEEC-UNAM/ FACULTAD DE ECONOMÍA-UNAM/ INSTITUTO DE GEOGRAFÍA-UNAM/ PLAZA Y VALDÉS MÉXICO, 2006, pp. 408. \\ Federico Morales Barragán PROIMMSE-IIA-UNAM
}

\section{MACRODETERMINISMO Y ANÁLISIS ECONÓMICO REGIONAL}

El libro coordinado por Felipe Torres y José Gasca acerca de la situación del sur-sureste mexicano y sus posibilidades de desarrollo a partir de la puesta en marcha del Plan PueblaPanamá propicia la discusión en torno a las estrategias de análisis que postulan la preeminencia de las estructuras o procesos de carácter macro sobre aquellos de carácter micro. Esta discusión de por sí relevante resulta de especial interés en el ámbito del análisis económico regional pues aborda uno de sus temas fundamentales: cómo se articulan las tendencias generales con los procesos particulares en la evolución de las economías regionales. Desde ahora conviene advertir que aquí no se propone una discusión que enfrente de manera estéril las posiciones funcionalista y reduccionista, recientemente Abbott (2006) se ha ocupado de este debate de manera sugerente mediante el uso del concepto de emergencia desde la perspectiva de las ciencias de la computación; más bien, el propósito de esta reseña es plantear algunas consideraciones en torno al enfoque general que, en mi opinión, está presente en el libro coordinado por Torres y Gasca. 
Los espacios de reserva, forma en que será denominado el libro objeto de esta reseña, integra las contribuciones de una decena de especialistas, las cuales se organizan en tres partes y un apéndice. La primera de ellas contiene una interpretación de la división internacional de los territorios y las exigencias, fruto de las tendencias globales, a las que aquellos están sujetos. Además se ofrece un perfil de la estrategia de desarrollo regional conocida como Plan Puebla-Panamá (PPP). En la segunda parte se caracteriza la región sursureste de México reflexionando acerca de su papel en los procesos de integración hemisférica, la distribución subregional de la inversión privada, la generación de energía eléctrica y los rasgos del sistema urbano-regional de asentamientos humanos. La parte tercera aborda tres asuntos reiteradamente discutidos, aunque muchas veces no de manera acuciosa: el uso de los recursos naturales, las tendencias migratorias recientes y la respuesta social que se opone al PPP. Finalmente las dos contribuciones que integran el apéndice caracterizan la región de estudio con base en la propuesta de un índice de desarrollo socioeconómico y mediante indicadores de transporte útiles para medir la interconectividad y accesibilidad de aquélla. No está de más señalar que la sección correspondiente al índice de competitividad que se presenta en uno de los capítulos de la segunda parte, el que se ocupa de la distribución subregional de la inversión privada, hubiera tenido, en mi opinión, una mejor ubicación en este apéndice final.

El argumento identificable en Los espacios de reserva sostiene que una estrategia de desarrollo regional como la expresada en el PPP no es viable en una región subdesarrollada como la del sur-sureste de México. Este argumento se construye con base en tres elementos: una estrategia de análisis que da preeminencia a explicaciones sobre tendencias generales presentes en el capitalismo contemporáneo, la sistematización de información 
referida al PPP proveniente de fuentes gubernamentales y de organismos multilaterales, y la caracterización de tres facetas socioeconómicas de la región de estudio mediante el uso de información estadística disponible. En esta reseña me ocuparé sobre todo del primero de los elementos señalados.

En Los espacios de reserva se argumenta que el modelo actual de expansión global del capital tiende a generar procesos de revalorización de los territorios que dependen fundamentalmente de factores que les son exógenos y poco o nada responden a las necesidades de quienes los habitan.

La segmentación internacional de los procesos productivos orientados hacia el mercado externo determina que las operaciones se realicen de manera simultánea en diferentes unidades de producción, localizadas en diversos países, segmentando así las cadenas productivas e internacionalizándolas, lo que implica una revalorización del nuevo espacio hasta ahora ubicado como reserva del capital [...] Dicha segmentación parte de la idea de que la producción local solo tiene sentido en un contexto global (p. 33).

Desde esta perspectiva la región sur-sureste de México constituye un espacio de reserva susceptible de ser revalorizado, para ello se requiere poner en marcha una estrategia acorde con la lógica del modelo actual de expansión global del capital; este es el contexto en el que se ubica el diseño del PPP.

Según el enfoque general identificado en Los espacios de reserva, el macrosistema capitalista no solo determina fuertemente las estructuras y procesos regionales, también se concibe como una totalidad indiferenciada, de ahí que la evolución económica de una 
región dependa fundamentalmente de la lógica que rige dicha totalidad. Al respecto conviene tener presente algunas evidencias que conducirían a matizar esta opinión.

\begin{abstract}
A pesar de la recurrente alusión a la globalización en gran parte de los discursos y análisis económicos, la gran mayoría de la producción en el mundo no tiene como destino final los mercados internacionales. Según datos recientes del Banco Mundial, tan solo el 23,2\% de la producción mundial en el año 1999 son exportaciones de bienes y servicios, o lo que es lo mismo, más del 76\% de la producción internacional se realiza en mercados internos. En América Latina y el Caribe el promedio del porcentaje de las exportaciones de bienes y servicios respecto a la producción interior bruta es del $17,4 \%$ en el año 2000, esto es, casi el $83 \%$ de la producción latinoamericana tiene como destino el mercado interno [...] (Alburquerque 2004: 2).
\end{abstract}

Lo expresado por Alburquerque muestra la conveniencia de valorar con mayor cautela las proposiciones frecuentemente escuchadas acerca de la globalización. Con la misma intención enseguida se hace referencia a enfoques que cuestionan el carácter indiferenciado de la lógica atribuida al sistema capitalista.

En contraste con el enfoque identificado en Los espacios de reserva, el estudio de las modalidades de evolución económica regional registradas en otras latitudes ha conducido a reconocer distintas formas en el capitalismo contemporáneo (Amable 2002, Aoki 2001, Jones 1999, Quadrio Curzio y Fortis 2002). Este carácter diferenciado del capitalismo proviene en buena medida del efecto significativo que ejercen las diversas instituciones en la configuración de las relaciones sociales. Tal diversidad refleja, como señala Amable (2002), el hecho de que no existe un único camino para la economía capitalista moderna, por el contrario, es posible la coexistencia de distintas variedades del capitalismo. 
La visión de un capitalismo indiferenciado sugiere, por el contrario, la posibilidad de construir un entorno institucional ideal al margen de las condiciones particulares de cada país y región. Como señala el propio Amable, esta perspectiva ignora que la influencia de las instituciones en las relaciones sociales no ocurre independientemente una de la otra y, por ello, asume la posibilidad de construir un entorno institucional ideal como si en la realidad pudiera jugarse al "mecano institucional". Si esto fuera posible

[...] la economía ideal [tendría] el sistema educativo de Dinamarca; la política de empleo y de tecnología de Suecia; el ambiente competitivo del sector de alta tecnología de Finlandia; y el ambiente empresarial, la flexibilidad salarial, [las condiciones de] protección al empleo, el sistema fiscal, el ambiente competitivo, las economías de escala y la productividad de los Estados Unidos (2002: 5).

La referencia a los estudios que ponen en entredicho la homogeneidad del capitalismo tiene como finalidad llamar la atención sobre los alcances de una estrategia de análisis orientada a explorar detalladamente el funcionamiento de las instituciones y su efecto en la evolución de las economías regionales. Los alcances de esta tarea tienen que ver, entre otras cosas, con la posibilidad de entender las bases diferenciadas sobre las que puede construirse el desarrollo regional en América Latina.

Esta discusión resulta pertinente para comentar el segundo elemento que da sustento al argumento general de Los espacios de reserva, esto es, la sistematización de información referida al PPP proveniente de fuentes gubernamentales y de organismos multilaterales.

El estudio detallado de las instituciones y su efecto en la evolución de las economías regionales pondría en tela de juicio la supuesta coherencia del PPP que se desprende de la 
información proveniente tanto de organismos gubernamentales como multilaterales. A partir de esas fuentes de información toda acción pública y privada llevada a cabo en la región parecería responder a los objetivos y metas propuestos en el PPP. El análisis de los cambios de la trama institucional, por demás heterogénea, que rige las relaciones de los actores que habitan o están vinculados con la región sur-sureste de México, pondría de manifiesto que la evolución económica de la región no se rige por un único patrón y mucho menos que este proviene de los lineamientos establecidos en el PPP. La ausencia de mecanismos de coordinación efectiva entre los actores involucrados en la ejecución de esos lineamientos es uno de los rasgos que caracteriza el funcionamiento del citado plan.

Un último y muy breve comentario se refiere a la caracterización socioeconómica de la región sur-sureste de México ofrecida por varias contribuciones del libro aquí reseñado. Simplemente señalo que ojalá en otra ocasión los autores puedan ofrecernos una reflexión dedicada a comparar los resultados obtenidos mediante el cálculo de los índices de competitividad, de desarrollo socioeconómico y de transporte, así como por la caracterización del sistema urbano-regional.

\section{REFERENCIAS}

Abbott, Russ, 2006, Emergence Explained: Getting epiphenomena to do real work. Department of Computer Science, California State University, http://132.236.180.11/ftp/cs/papers/0602/0602045.pdf

Alburquerque, Francisco, 2004, Teoría y práctica del enfoque del desarrollo local. Encuentro Internacional Desarrollo local en un mundo global, http://www.eumed.net/eve/ 
Amable, Bruno, 2002, Is there an institutional base of the new economy? University of Paris X and CEPREMAP, http://www.jourdan.ens.fr/ amable/TORONTO2.pdf

Aoki, Masahiko, 2001, Toward a Comparative Institutional Analysis. The MIT Press Cambridge.

Jones, Martin, 1999, New Institutional Spaces. TECs and the Remaking of Economic Governance. Regional Studies Association/Jessica Kingsley Publishers, London.

Kontopoulos, Kyriakos M., 1993, The Logics of Social Structure. Cambridge University Press, Cambridge.

Quadrio Curzio, Alberto y Marco Fortis, 2002, Complexity and Industrial Clusters. Dynamics and Models in Theory and Practice. Physica-Verlag, Heilderberg.

Screpanti, Ernesto, 2001, The Fundamental Institutions of Capitalism. Routledge, London. 